\title{
Listening and shouting
}

\author{
Stephen Hancocks OBE \\ Editor-in-Chief
}

The BDJ Upfront section includes editorials, letters, news, book reviews and interviews. Please direct your correspondence to the News Editor,

Kate Quinlan at BDJNews@nature.com. Press releases or articles may be edited, and should include a colour photograph if possible.

$\mathrm{T}$ he invention of the generation gap is often credited to the 1950 s and 1960 s when teenagers became rebellious coincident with the emergence of rock music and greater freedoms. In reality I suspect that the divide has been there since the dawn of time and it was only the marketing term that we can attribute to those now nostalgic days of swing and Beatlemania.

Identifying a divergence of views between age groups has probably become more apparent as the speed of change in society has accelerated. As new ideas, moral attitudes, technologies, economic circumstances and a whole raft of other contributory factors have come into play so too have the opportunities arisen for younger people to express what they regard as more modern outlooks compared to older people who are branded as out of date. In recent times this has seemed to apply particularly in dentistry. For a while now I have been hearing newly qualified dentists complaining that older colleagues seem intent on talking up the good old days when they did 'proper' dentistry for a decent return. Coupled with accusations that contemporary graduates do not know how to provide various treatments, this has provided a background of some begrudgement.

So, rather reassuring but for various other reasons that you will read in this issue also very alarming, that the young and the not-soyoung are finding themselves very much on the same side. The two 'opinion' pieces in this issue were unsolicited and were submitted completely independently but show what I believe is a remarkable synergy. Using politically correct terminology, one of the authors, Martin Kelleher, is a more mature and much respected dentist who in his own words is nearing the end of his (very distinguished) career. Ali Al Hassan, by contrast is a young dentist at the outset of his working life in dentistry. What I found so arresting about these two essays is the confluence of their content, right down to the use of the word 'fear' at the centre of both of them, coupled with sentiments of disappointment, betrayal and disillusionment.

In some ways I would urge you to turn to them and read them both before you return to read the rest of this editorial as I do not want to steal the power of their words or dilute the impact of their messages. Whether you do or not, I hope that by the time you read and digested these pieces you will have pause for thought. I suspect that they will have very wide resonance amongst readers. If that is the case then I am both saddened by the state of affairs but hopeful that at least by identifying the problems we can, together, find ways of improving the situation.
Until now, I have been under the impression that new graduates were still enthusiastic about the future of dentistry. Our young colleagues are clever, switched-on individuals whose motivation to enter the profession is predicated on caring for patients and making positive differences. But it is with great regret that I sense they are now starting to question the way in which the General Dental Council (GDC) in particular is expecting them to work with the fear of retribution lurking behind every dental chair. The recent and ongoing elections to the BDA committees have been particularly hotly contested by the Young Dentists and this does give me hope that they will engage with the political process and attempt to resolve some of these barriers to them enjoying a long and ful-

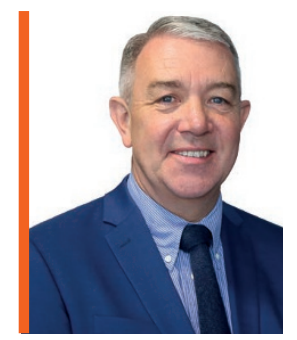

\section{'The GDC should hang its head in shame that far from protecting patients it is effectively diminishing the care available to them...'}

The essence of the two pieces is that the profession of dentistry is under siege from a range of pressures applied due to economics, regulation, litigation and more from a number of agencies and bodies. These have, consciously or by default served to comprehensively undermine the confidence of the profession which over decades has been built by caring, conscientious practitioners whose patients (key point) still have the most demonstrable trust in us. This really is a terrible state of affairs. It is terrible not just for us, but more importantly the effect that it is having on the patients in our care as defensive practice systematically reduces choice and stifles clinical freedom to pursue appropriate individual treatment options. filling career. Although as $\mathrm{Al}$ Hassan notes, it is already too late for some. That is a catastrophic waste and the GDC should hang its head in shame that far from protecting patients it is effectively reducing their choice and diminishing the care available to them.

Is this 'state-sponsored dental terrorism' as Kelleher terms it, a reversal of Bernard Shaw's conspiracy against the laity; a connivance by the laity, or at least by its elected and unelected representatives? Or is it merely an unfortunate conflict caused by diverse interests considering professional care but not paying attention to care for the professional? The call for the call to action is getting louder. We need to not only listen but also to shout.

DOI: 10.1038/sj.bdj.2017.1003 